\title{
The Japanese Experience in Building the System of Human Resource Quality Management in the Organization
}

\author{
Irina Lyskova ${ }^{1, *}$ \\ ${ }^{1}$ Department of Economics and Management, The Komi Republic Academy of State Service and Administration, \\ Syktyvkar, Russia \\ "Corresponding author. E-mail: IrinaLyskova@mail.ru

\begin{abstract}
The article focuses on the issues of quality management and justifies the importance of developing the approaches to human resource management and the need to establish the human resource quality management system of the organization in the current socio-economic conditions. The objective of the study is to analyze the Japanese experience in building the system of human resource quality management and to identify the specific features of the Japanese human resource quality management of the organization. The conclusion is made on the value of the Japanese experience in developing the effective system of human resource quality management and the potential of the application of the Japanese practices in Russia.
\end{abstract}

Keywords: organization, management, Japanese management, human resource management, quality

management, human resource quality

\section{INTRODUCTION}

Since the second half of the 20th century, there has been a growing interest in the issues of business process efficiency, organizational development, motivation and labor productivity in the conditions of limited resources. Modern life and its fast-paced development require business to introduce new methods and technologies aimed at increasing customer satisfaction, adapting to changes and challenges of the competitive environment, ensuring production profitability and meeting modern quality standards [1] [2] [3] [4]. Particular attention in this respect should be given to the issues of human resource quality of the organization.

For over 70 years, Japanese corporations have been applying a unique management model, the centre of which is human resources and their role in business processes, the value of the humanistic approach in production activity, and the encouragement of partnership, cooperation, engagement, responsibility and leadership.

Kosuke Motani, a well-known Japanese economist, Senior Researcher at the Japan Research Institute, Special Adviser to the Regional Planning Department of the Development Bank of Japan and a lecturer having visited several countries, Russia in particular [5], states that one of the distinguishing characteristics of Japan is its high level of demographic and social maturity. Extended life expectancy and the increase in aging population associated with it, resulted in Japan facing substantial falls in workforce. Production rates and volumes remain high, but the consumption is decreasing, especially in the domestic market of the country. Therefore, the measures intended to introduce innovations and ensure the continuous growth of the Japanese economy are being taken. Traditionally, the source of such innovations in Japan is people.

Russia is a country with enormous potential, occupying a vast territory and rich in natural resources. Today it is facing serious political, economic and social risks, which, however, can be reduced by means of effective human resource management practices. We assume that the Japanese management rationally applied to Russian conditions (especially in terms of developing corporate and professional culture and organizational behavior) can establish the framework for this process.

Therefore, it is critical to understand the nature of the Japanese management, reveal the secret behind the success of the Japanese quality management, analyze the Japanese experience of developing the human resource quality management system and consider the prospects of its application in Russian conditions. 


\section{THEORETICAL AND METHODOLOGICAL APPROACHES TO THE ASSESSMENT OF HUMAN RESOURCE QUALITY IN THE ORGANIZATION}

The last quarter of the 20th century was the time of the widespread introduction and development of human resource management. Currently, it is the basis for personnel work at the state, regional, sectoral and organizational levels. Human resource management comprises numerous approaches to attracting, using and developing human resources, including the systemic, strategic, regulatory, marketing, competence, and behavioral ones. The system of human resource management covers workforce planning, compliance with legal norms, development of a human resource policy, social development of the organization, etc. Another important function is unlocking and fulfilling professional, intellectual, creative and entrepreneurial potential of employees when aiming for business targets. It implies the establishment of favorable working conditions, maintenance of work discipline, facilitation of effective communication, creation of positive social and psychological atmosphere, etc. Human resource development in modern conditions is competence-based; it involves professional competence development in employees and stimulation of their personal growth, and covers personnel assessment, employee training, retraining and advanced training, career management, maintenance of talent and candidate pools, etc. [6] [7].

In the context of a market economy, a new aspect of human resource development - increasing the quality of human resources in the organization - has been brought into focus. The existing human resource management system has acquired a new function quality management, including human resource quality management. Accordingly, the methodological basis for human resource quality management is amplified by the ideas of quality management, life quality, working life quality, etc. [8] [9] [10]. The totality of the factors of the global, regional, sectoral and organizational level determines the targets, functions, principles, methods, and technologies of modern work with human resources [11] [12]. The analysis of the Japanese experience contributes to the understanding of state, organizational and personal objectives, the content and methods of establishing the human resource quality management system of the organization [13] [14] [15].

\section{SPECIFIC FEATURES OF THE JAPANESE SYSTEM OF HUMAN RESOURCE QUALITY MANAGEMENT IN THE ORGANIZATION}

The Japanese business model is a unique example of profound qualitative changes affecting individual and collective identity, establishing entirely new cognitive approaches to labor management and effective ways of ensuring the quality of business processes. In 1960s70 s, Japanese managers started implementing strategic thinking principles, working out strategic development plans based on strategic creativity rather than rigid planning, as was customary in the United States of America, for instance. The Japanese strategic planning system was focused on business interests, was consumer-oriented and took account of competitor companies. The main strategic idea of organizing business was the understanding of consumer needs and their satisfaction in the best possible way, being ahead of competitors. Back in late 1960s - early 1970s, the Japanese were thought to follow the Western way of doing business, but then in a decade they made a breakthrough in the development of new goods and services and thereafter became recognized as innovators and strategists.

It is important to highlight that the Japanese human resource management system was largely influenced by Joseph M. Juran and W. Edwards Deming, the outstanding American specialists in management.

In the late 1940s, on the initiative of Kaoru Ishikawa, the Union of Japanese Scientists and Engineers (JUSE) was created and included a quality management committee. In 1950 and later, W. Edwards Deming visited Japan on numerous occasions to deliver lectures on quality management issues. He introduced Japanese specialists to the American management system, which ensured a high level of production efficiency and labor productivity. In 1954, invited by the Union of Japanese Scientists and Engineers, Joseph M. Juran visited Japan for the first time and paid special attention to the objectives of improving management efficiency. The quality management system emerging in Japan developed into a unique practice of quality circles, the first one established in 1962.

Initially, the new quality management system was applied in mechanical engineering and the automotive industry. Later it spread into industries producing durable goods and home appliances. Today, the quality management system, high productivity and labor efficiency are the integral characteristics of any industry. The quality management system implies deep understanding of the system of labor management, engagement in production process, and orientation towards progressive and continuous improvement of systems and processes.

The modern Japanese management model is associated with the theory and practice of kaizen. Translated from Japanese, "kaizen" means "continuous improvement". The concept includes the ideas of continuous improvement of personal, family, social and work life. With regard to the production area it implies the engagement of all employees of the organization in its development process. 
Kaizen should be primarily seen as a management idea aimed at people, the core of the Japanese management model. The philosophy and practice of kaizen are based on the humanistic approach that allows rethinking and reinterpreting the role of a person in the organization. Deep qualitative changes in human resource management are achieved due to the changes in professional and personal attitudes of employees (starting with the management of the organization) and full acceptance and adherence to the philosophy of kaizen. The main business recipe for preventing problems is following high quality standards. The main function of managers in the organization is constant development of processes, full admission of their leadership responsibility, and partnership development in the team.

Organizational behavior models of high professional culture are characterized by unique strategic thinking styles. The Japanese style of thinking is based on the dynamic interaction between the company, its customers and competitors. This process involves deep creative, often intuitive, understanding of the circumstances, and rejecting standard, stereotypical thinking. The Japanese strategic thinking is fundamentally different from the Western model of management, with its rigid rules, procedures, standards and regulations.

\section{HUMAN RESOURCE QUALITY MANAGEMENT SYSTEM IN TOYOTA}

A unique example to attract genuine interest of managers, businesspersons, and specialists in various fields is the world famous Toyota Production System (TPS), and its human resource management system, in particular [16] [17] [18].

The history of the company is connected with the Toyoda family business. Initially, the family was involved in weaving. In 1894, Sakichi Toyoda made his first wooden loom with a steam engine, and in 1926, they launched the production of automatic weaving machines. According to Jeffrey Liker [19], Sakichi Toyoda was a great inventor, though his main contribution to the establishment of Toyota was his philosophy and approach to work, based on striving for continuous improvement. Self-Help, a book by Samuel Smiles [20], published in 1859 in England and in 1860 in the USA, had a significant influence on Sakichi Toyoda, as it discussed and justified the value of hard work, discipline, frugality, learning, and selfimprovement. Meanwhile, it was exactly in England, where the international movement for the spread of university education (university extension) originated; it promoted the value of general and professional education and gradually became widely known, including in Russia [21].
In 1930, Kiichiro Toyoda took over his father's business. Having received engineering education at the Tokyo Imperial University, he started working in mechanical engineering and with the money earned from the sale of a patent, created an automobile company.

Eiji Toyoda and Taiichi Ohno, the chairman and director of Toyota Motor Manufacturing (later Toyota Motor Corporation) are considered the founders of the highly efficient production system of Toyota. The idea of the new Japanese production system based on the "just-in-time" principle and production automation, emerged when Eiji Toyoda and Taiichi Ohno visited the USA supermarkets, where they saw customers taking goods from the shelves. T. Ohno considered the possibility of the application of the methods of American supermarkets to the car manufacturing process. The management of the company recognized the importance of adapting advanced technologies of American manufacturing focusing on high quality of products, low prices, reduced development time and maximum flexibility.

In the 1950s, Shigeo Shingo, Genichi Taguchi and Kaoru Ishikawa started cooperation with Toyota and made a significant contribution to the development of the basic management principles of the company. In the 1960s, the Toyota Production System evolved into a sophisticated system to be applied to any business or process.

In the early the 1970s, the Japanese government initiated thorough analysis of the experience of Toyota and its further implementation in other companies. The main goal was to defuse the crisis in the Japanese economy, which was largely affected by the global economic crisis. The United States considered the application of Toyota experience too, although the TPS did not lead to the expected results. A new wave of the interest in the Japanese management practices emerged in the early 1980s: the lean manufacturing model was brought into focus, which further developed into ISO international quality standards.

To identify the role of human resources in the business processes of Toyota, it is important to understand that the management of this company is an integral production system, rather than a set of individual techniques and methods of work. The Toyota quality improvement methods are widely known: justin-time, kaizen, one-piece flow, jidoka (quality control system) and heijunka (smooth production flow) are associated with the practice of lean manufacturing. However, applied separately, they do not provide profound qualitative changes. The success of Toyota is primarily associated with a unique business philosophy, which is based on the recognition of the human resources role and the effective system of work motivation. For years, Toyota has been developing and 
perfecting its business philosophy and culture and the models of leadership and teamwork.

The TPS is often associated with a "house" concept. In order for a house to be structurally safe, the foundations are needed - a building base, supports, and a roof. The base of the TPS is its unique philosophy, customer-focused production culture, business process visualization, and standardized processes that ensure high quality. The supports are the just-in-time technology and jidoka, that is, a technology aimed at automating production and protecting the company from delivering products of low quality or defects to the customers. The roof of the Toyota Production System is associated with its strategic goals aimed at excellent quality, low costs, and high levels of safety, morale and professional culture of the company's employees.

Each of the outlined elements is important in itself; however, it is a comprehensive approach that ensures maximum business process efficiency. The core of the unique management system of Toyota is its people, fully engaged in activities and motivated to continuously develop their personal competence and improve the production process.

It is essential to emphasize the basic principles of Toyota management, which build the system of production culture, human resource quality management and organizational behavior, as they are expected to be practical and relevant for the organizations striving to achieve the maximum.

According to J. Liker, the management principles of the TPS are grouped into the following categories:

- Long-term philosophy;

- The right process will produce the right results;

- Add value to the organization by developing your people;

- Continuously solving root problems drives organizational learning. [19, p. 72-78].

The first category of principles of the Toyota Production System, Long-term philosophy, consolidates the foundations of industrial culture in employees and is associated with the implementation of the system and strategic approaches to decision-making. The second category combines a wide set of principles that ensure correct process organization and the ability to achieve the expected results. The production system is aimed at the development of strong organizational culture, effective communication, technological process and rational labor management. The third category of principles revealing the specifics of the TPS implies adding value to the organization by developing its employees and partners. The management of the organization recognizes the importance of growing leaders within the company, promoting committed professionals with responsible attitude to business, able to develop the company's philosophy. The fourth category of Toyota principles is associated with the constant need to solve problems, which in turn stimulates the development of continuous professional training and personal improvement by means of the methods of self-reflection (hansei) and continuous improvement (kaizen).

Toyota experience of building the efficient production system characterized by the combination of philosophy, process, human resource and problemsolving technologies, encourages the organization of lean, learning, continuously developing production. Due to Toyota, lean management has received widespread recognition, and combined with Six Sigma, has become a recent trend. However, most companies pay attention to individual tools only ( $5 \mathrm{~S}$, just-in-time system, etc.), underestimating the importance of creating an integral culture of the organization and ensuring the engagement of all participants in the production process. The development and implementation of a new production model to follow the Japanese experience presupposes a profound and comprehensive transformation of philosophy and corporate culture of the organization [22].

The most general characteristics of the Japanese management and the basic principles of the TPS emphasize the role of human resource of the organization in achieving high performance, quality, and competitiveness. The TPS is a unique example that laid the foundations for the Japanese quality management in general and the human resource quality system, in particular.

\section{CONCLUSION}

The difficulty in adapting the approaches of Toyota to developing the quality management system in other organizations, especially outside of Japan, was that the companies mostly focused of improving processes only, neglecting the philosophy and long-term prospects, not giving enough attention to employee development and underestimating the atmosphere of openness and the importance of continuous employee improvement and training.

Nevertheless, following the Japanese practice of building a human resource quality management system blindly is unlikely to provide the desired effects either. In the time of serious political and socio-economic problems, Japan, adapted and rationally applied the best practices of the Western management, thus having developed its unique approaches to ensure development and quality. Currently, the West is analysing the experience and achievements of Japan. With regard to modern Russia, it is important to consider the experience of the Japanese management in the context 
of the increasing role of strategic planning, human resources and their retention, importance of favorable working conditions, employee engagement, and open production processes; the development of labor motivation and professional culture of all participants of the production process.

To conclude, the modern objectives of management are inseparably associated with the need to establish the effective quality management system, the core element of which is human resource quality management. The targets of developing the quality of human resources at the state level are identified by the need to create the innovative and competitive economy, develop a knowledge economy, and improve the quality of life of the population. The creation of the human resource quality system will ensure the application of the innovative and creative potential of employees for the purpose of competitiveness and production efficiency. No less important are individual goals related to effective self-realization and full development of individuals in the area of labor activity, increasing engagement, satisfaction, and competitiveness in a market economy, etc. The analysis, generalization and creative implementation of the Japanese business model can provide ample opportunities for qualitative changes in business processes at the individual, group and company level in almost any organization [23] [24]. An illustrative example in this respect is the State Atomic Energy Corporation Rosatom, which successfully introduces the philosophy and basic principles of the Toyota production system into its practice.

\section{References}

[1] Adizes, I. S. (2016). Mastering Change. The Power of Mutual Trust and Respect in Personal Life, Family Life, Business and Society. Moscow. Mann, Ivanov and Ferber. -368 p.

[2] Cokins G. (2016). Performance management. Finding the missing pieces (to close the intelligence gap) Moscow: Al'pina Pablisher. $-316 \mathrm{p}$.

[3] Evans, V. (2015). Key strategy tools. The 80+ tools for every manager to build a winning strategy. PEARSON. Moscow: BINOM. Laboratoriya znaniy. $-456 \mathrm{p}$.

[4] Marr B. (2014). Key performance indicators. The 75 measures every manager needs to know. PEARSON. Moscow: BINOM. Laboratoriya znaniy. $-340 \mathrm{p}$.

[5] Lyskova I. (2019). Psychological Basis of Human Resources Quality Management in a Modern Organization // Advances in Economics, Business, Management Research / Proceedings of the 2 th International Conference on Economy, Management and Entrepreneurship (ICOEME 2019) Atlantis Press, 2019, V. 85. P. 299-302.

[6] https://www.krags.ru/priglashaem-na-seminar-nauchnogosotrudnika-iz-yaponii-kosuke-motani/

[7] Lyskova I. (2018). The Art of Creative Thinking as a Basis of Modern Labor Philosophy // Advances in Social Science, Education and Humanities Research. Vol. 252 // Proceedings of the 3rd International Conference on Judicial, Administrative and Humanitarian Problems of State Structures and Economic Subjects (JAHP 2018) Atlantis Press, 2018, P. 266-270.
[8] Lyskova, I.E. (2017). The Main Paradigms of Human Resources Quality Management in the Aspect of Modern Cognitive Economy. The Herald of the Management Faculty of the Sain Petersburg State University of Economics. 2017, vol. 1. P.1. P. 60-65.

[9] Lyskova, I.E. (2017). The problems of human capital management in the aspect of modern knowledge economy. Journal of economy and entrepreneurship. 2017. No. 9 (P. 4) (84-4). P. 641-645.

[10] Lyskova, I.E. (2017). Intellectual Technologies as the Basis of the Innovative Model of Management of Quality of Human Resources of the organization. National Concepts of Quality: the Integration of Education, Science and Business. The Collection of Articles of the VIII International Research and Practice Conference. Saint Petersburg, 2017. P. 99-102.

[11] Sherwood, D. (2016). Seeing the forest for the trees. A Manager's Guide to Applying Systems Thinking. Moscow: Al'pina Pablisher. - 300 p.

[12] O'Connor, J. McDermott, I. (2015). The art of systems thinking. Essential skills for creativity and problem solving. Moscow: Al'pina Pablisher. - 256 p.

[13] Lyskova I. (2018). Quality of working life in the aspect of human resources management // Advances in Economics, Business, Management Research / Proceedings of the 4 th International Conference on Economics, Management, Law and Education (EMLE 2018) Atlantis Press, 2018, V. 71. P. 226230.

[14] Lyskova I. (2017). Main Paradigms of Creative Management in the Aspect of Modern Cognitive Economy // Proceedings of the International Conference on Culture, Education and Financial Development of Modern Society (ICCESE 2017) Vol. 103 Atlantis Press, Amsterdam-Hong Kong-Paris. 2017. P. 644-649.

[15] Lyskova I. (2018). Mental Reengineering as an Intellectual Technology of a Human Resources Quality Management in a Modern Organization // Advances in Social Science, Education and Humanities Research. Vol. 205 / Proceedings of the 2nd International Conference on Culture, Education and Economic Development of Modern Society (ICCESE 2018) Atlantis Press, 2018, P. 903-906.

[16] Lyskova I. (2018). The Japanese Model of Strategic Management of Human Resources Quality in a Modern Organization // Advances in Economics, Business, Management Research / Proceedings of the 4 th International Conference on Economics, Management, Law and Education (EMLE 2018) Atlantis Press, 2018, V. 71. P. 231-234.

[17] Ohmae. K. (2015). The Mind of the Strategist. The Art of Japanese Business. Moscow. - 211 p

[18] Imai, M. (2015). Kaizen. The Key to Japan's Competitive Success. Moscow: Al'pina Pablisher.- 274 p.

[19] Liker J. (2017). The Toyota Way. 14 Management Principles from the World's Greatest Manufacturer. Moscow: "Tochka". $400 \mathrm{p}$.

[20] Smiles S. Self-Help: With Illustrations of Character, Conduct and Perseverance. New York: Harper and Broders, 1860 Published as Self-Help (Peter W. Sinnema, editor). New York: Oxford University Press, 2002.

[21] Blinov A.O., Lyskova I.E. (2016). International Public Activity in Favor of Spreading University Education as a Social Innovation in the Period from the End of 19th up to the Beginning of 20th centuries. Alma Mater. Vestnik Vysshei Shkoly. No. 10. P. 85-92.

[22] George M. (2016). Lean Six Sigma for Service. How to Use Lean Speed and Six Sigma Quality to Improve Services and Transactions. Moscow: Mann, Ivanov and Ferber. 2017. - 464 p. 
[23] Lyskova I.E. (2018). The main problems of forming the effective behavioral models of employees in the aspect of human resources quality management (Using the Example of «Rosatom» State Corporation). Global Nuclear Safety. No 4 (29). P. 109-117.

[24] Lyskova I.E. (2019). The introduction of models of sustainable development and lean production in ecological and social safety system in a modern organization (Using the Example of «Rosatom» State Corporation). Global Nuclear Safety. No 4 (33). P. 85-95-117. 